\title{
Multivessel Coronary Artery Disease and Subsequent Thrombolysis in Myocardial Infarction Flow Grade After Primary Percutaneous Coronary Intervention
}

\author{
Haris Majeed ${ }^{1}$, Muhammad N. Khan ${ }^{2}$, Khalid Naseeb ${ }^{1}$, Najia A. Soomro ${ }^{3}$, Saeed Alam ${ }^{2}$, Shahid Ahmed ${ }^{4}$ \\ , Usman Bhatti ${ }^{1}$, Tahir Saghir ${ }^{1}$ \\ 1. Cardiology, National Institute of Cardiovascular Diseases, Karachi, PAK 2. Interventional Cardiology, National \\ Institute of Cardiovascular Diseases, Karachi, PAK 3. Cardiology, Liaquat National Hospital, Karachi, PAK 4. Adult \\ Cardiology, National Institute of Cardiovascular Diseases, Karachi, PAK
}

Corresponding author: Muhammad N. Khan,muhammad.nauman@nicvd.org

\section{Abstract}

\section{Background}

In underdeveloped countries, coronary artery disease (CAD) has developed into a serious health issue due to the high rates of risk factors such as obesity and smoking amongst the population. This study has been performed to find the rate of multivessel CAD (MVD) and subsequent thrombolysis in myocardial infarction (TIMI) flow grade III in patients undergoing primary percutaneous coronary intervention (PCI).

\section{Methods}

This transverse study was carried out involving 110 patients from the emergency department of the National Institute of Cardiovascular Diseases, Karachi, Pakistan, from August 2015 to March 2016. All patients were diagnosed as ST-segment elevation myocardial infarction (STEMI) and had gone through primary PCI. Preprocedure angiographic findings regarding the number of vessels involved and post-procedure TIMI flow grade were assessed and analysed.

\section{Results}

The average age of the study sample was $56.3 \pm 11.4$ years. The proportion of male patients was $81.8 \%$ $(\mathrm{n}=90)$, and hypertension was the most prevalent risk factor followed by type II diabetes with a frequency of $67.3 \%(n=74)$ and $40.0 \%(n=44)$, respectively. Coronary angiography showed MVD in $50.0 \%(n=55)$ of the patients, of whom 34 patients had two-vessel disease, and the remaining 21 had three-vessel disease. Ninety percent $(n=99)$ of the patients exhibited TIMI flow grade III after the procedure with no significant difference between patients with MVD and those with single-vessel disease with a rate of $87.3 \%(n=48 / 55)$ versus $92.7 \%(\mathrm{n}=51 / 55, \mathrm{P}=0.527)$, respectively.

Received 05/28/2020

Review began 06/06/2020 Review ended 06/12/2020 Published 06/21/2020

\section{(c) Copyright 2020}

Majeed et al. This is an open access article distributed under the terms of the Creative Commons Attribution License CC-BY 4.0, which permits unrestricted use, distribution, and reproduction in any medium, provided the original author and source are credited.

\section{Conclusion}

Post-procedure TIMI flow grade III was accomplished in almost 90\% of the subjects with or without MVD. It can be concluded that primary PCI has a significant role in the early restoration of myocardial blood flow following STEMI regardless of the vessels involved.

Categories: Cardiology

Keywords: coronary artery disease, multivessel disease, primary pci, timi flow

\section{Introduction}

Globally, cardiovascular diseases (CVDs) claim the highest number of lives and significantly contribute to poor quality of life each year [1]. In 2017, CVDs claimed 17.8 million lives and 35.6 million years of life lost due to disabilities $[2,3]$. Nearly $80 \%$ of this global burden consists of low- and middle-income populations [4].

The populations of South Asian countries are at the highest risk of developing the CVD; therefore, they experience the highest rates of death across the world [5-7]. Due to the fast growth of cities in this part of the world, more people have moved to urban centers. This has resulted in a spike of coronary artery disease (CAD) occurrence, and therefore it becomes essential to study, analyse, and understand which internal and external factors cause a high risk of disease so that strategies to prevent the disease may be developed [5].

The high rates of CAD in the South Asian population have been linked to an ongoing epidemiological transition and a higher prevalence of cardiac risk factors, such as hypertension (HTN), obesity, sedentary 
lifestyle, smoking, and type II diabetes mellitus (DM), in the region $[3,8,9]$.

According to multiple studies involving clinical trials and institutional registries, multivessel CAD (MVD) was documented in around half of the patients with acute myocardial infarction (AMI). CAD involving multiple vessels has been linked to increased chances of mortality and morbidity amongst patients suffering from the disease [10-12].

The thrombolysis in myocardial infarction (TIMI) flow grade assessment is the standard criterion for the evaluation of coronary reperfusion yield. TIMI flow grade II or III of the native artery after a primary percutaneous coronary intervention (PCI) is indicative of the procedure success. Post-procedure TIMI flow grade III was found to be linked with decreased chances of death and morbidity, lower enzyme peaks, and improved global outcomes, including regional left ventricular function [13].

This study has been performed to find the rate of MVD and subsequent TIMI flow grade III in patients who have undergone primary PCI.

\section{Materials And Methods}

This cross-sectional study included 110 patients aged 18 to 82 years visiting the emergency department of the National Institute of Cardiovascular Diseases, Karachi, Pakistan, from August 2015 to March 2016. Patients of either sex with acute ST-segment elevation myocardial infarction (STEMI) were included using a nonprobability consecutive sampling technique. Informed consent was obtained from all the patients. Patients with a prior history of myocardial infarction (MI) were excluded.

Data regarding demographics (gender, age, height, and weight) and clinical characteristics were recorded for all the patients, which included a history of DM, HTN, dyslipidemia, smoking status, and family history of CAD. Body mass index (BMI) was calculated; clinical characteristics were defined based on clinical history. Patients with a documented history of HTN on antihypertensive medication for at least six months were categorized as hypertensive. Similarly, patients on medical therapy for DM for at least six months were categorized as DM. Patients were interviewed for the history of premature CAD in immediate blood relatives and last documented lipid profile, and dyslipidemia and family history of CAD were categorized.

After the diagnosis of STEMI, all the patients were managed as per the institutional protocols. Experienced cardiologists performed the primary PCI procedure. Patients with significant ( $>70 \%$ ) stenosis in more than one vessel were categorized as MVD. PCI was attempted for the culprit artery only, and post-procedure TIMI flow grade was recorded.

Data were analysed on IBM SPSS Statistics for Windows, Version 21.0 (IBM Corp, Armonk, NY). Age, height, weight, and BMI were presented as means \pm standard deviations (SDs), and frequency and percentages were presented for categorical variables including gender, DM, HTN, smoking status, dyslipidemia, MVD, and post-procedure TIMI flow grade. Effect modifiers like age, BMI, gender, DM, HTN, smoking status, and dyslipidemia were controlled through stratification. Post-stratification, appropriate chi-square test or Fisher's exact test was applied; a P value $\leqslant 0.05$ was considered significant.

\section{Results}

The average age of our study sample was $56.3 \pm 11.4$ years, with $52.7 \%(n=58)$ patients $\leqslant 55$ years of age. The proportion of male patients was $81.8 \%(\mathrm{n}=90)$, and HTN was the most prevalent risk factor followed by DM with a frequency of $67.3 \%(n=74)$ and $40.0 \%(n=44)$, respectively. The overall mean BMI of study subjects was $25.22 \pm 2.71 \mathrm{~kg} / \mathrm{m}^{2}$ (range, $18.4-36.782 \mathrm{~kg} / \mathrm{m}^{2}$ ). Coronary angiography showed MVD in 50.0\% $(\mathrm{n}=55)$ of the patients, of whom, 34 patients had two-vessel disease, and the remaining 21 had three-vessel disease. Table 1 presents the demographic information and clinical values by disease severity. 


\section{Cureus}

\begin{tabular}{|c|c|c|c|c|}
\hline & \multirow{2}{*}{ Total } & \multicolumn{2}{|l|}{ Disease severity } & \multirow{2}{*}{$P$ value } \\
\hline & & Multivessel disease & Single-vessel disease & \\
\hline Total & 110 & 55 & 55 & - \\
\hline \multicolumn{5}{|l|}{ Gender } \\
\hline Male & $81.8 \%(90)$ & $70.9 \%$ (39) & $92.7 \%(51)$ & 0.003 \\
\hline Female & $18.2 \%(20)$ & $29.1 \%(16)$ & $7.3 \%(4)$ & \\
\hline \multicolumn{5}{|c|}{ Age groups } \\
\hline$\leq 55$ years & $52.7 \%(58)$ & $50.9 \%(28)$ & $54.5 \%(30)$ & 0.702 \\
\hline$>55$ years & $47.3 \%(52)$ & $49.1 \%(27)$ & $45.5 \%(25)$ & \\
\hline \multicolumn{5}{|c|}{ Body mass index $\left(\mathrm{kg} / \mathrm{m}^{2}\right)$} \\
\hline$\leq 25$ & $57.3 \%(63)$ & $60 \%(33)$ & $54.5 \%(30)$ & 0.563 \\
\hline$>25$ & $42.7 \%(47)$ & $40 \%(22)$ & $45.5 \%(25)$ & \\
\hline \multicolumn{5}{|c|}{ Diabetes mellitus } \\
\hline Yes & $40 \%(44)$ & $47.3 \%(26)$ & $32.7 \%(18)$ & 0.119 \\
\hline No & $60 \%(66)$ & $52.7 \%(29)$ & $67.3 \%(37)$ & \\
\hline \multicolumn{5}{|c|}{ Hypertension } \\
\hline Yes & $67.3 \%(74)$ & $72.7 \%(40)$ & $61.8 \%(34)$ & 0.223 \\
\hline No & $32.7 \%(36)$ & $27.3 \%(15)$ & $38.2 \%(21)$ & \\
\hline \multicolumn{5}{|l|}{ Smoking } \\
\hline Yes & $48.2 \%(53)$ & $41.8 \%(23)$ & $54.5 \%(30)$ & 0.182 \\
\hline No & $51.8 \%(57)$ & $58.2 \%(32)$ & $45.5 \%(25)$ & \\
\hline \multicolumn{5}{|c|}{ Dyslipidemia } \\
\hline Yes & $31.8 \%(35)$ & $52.7 \%(29)$ & $10.9 \%(6)$ & $<0.001$ \\
\hline No & $68.2 \%(75)$ & $47.3 \%(26)$ & $89.1 \%(49)$ & \\
\hline \multicolumn{5}{|c|}{ Family history of coronary artery disease } \\
\hline Yes & $20.9 \%(23)$ & $36.4 \%(20)$ & $5.5 \%(3)$ & $<0.001$ \\
\hline No & (87) & $63.6 \%(35)$ & $94.5 \%(52)$ & \\
\hline
\end{tabular}

TABLE 1: Features of the demography and clinical values by severity of coronary artery diseases

Ninety percent of the patients exhibited post-procedure TIMI flow grade III with no significant difference between patients with MVD and those with single-vessel disease (SVD) with a rate of $87.3 \%(n=48 / 55)$ versus $92.7 \%(\mathrm{n}=51 / 55 ; \mathrm{P}=0.527)$, respectively. Table 2 presents demographic and clinical values by the severity of the TIMI flow grade III after the procedure. 


\section{Cureus}

\begin{tabular}{|c|c|c|c|}
\hline & \multicolumn{2}{|c|}{ Post-procedure TIMI flow grade } & \multirow{2}{*}{$P$ value } \\
\hline & III & $0-I I$ & \\
\hline Total & 90 & 11 & - \\
\hline \multicolumn{4}{|l|}{ Gender } \\
\hline Male & $92.2 \%(83)$ & $63.6 \%(7)$ & 0.112 \\
\hline Female & $17.8 \%(16)$ & $36.4 \%(4)$ & \\
\hline \multicolumn{4}{|l|}{ Age groups } \\
\hline$\leq 55$ years & $56.7 \%(51)$ & $63.6 \%(7)$ & 0.534 \\
\hline$>55$ years & $53.3 \%(48)$ & $36.4 \%(4)$ & \\
\hline \multicolumn{4}{|c|}{ Body mass index $\left(\mathrm{kg} / \mathrm{m}^{2}\right)$} \\
\hline$\leq 25$ & $62.2 \%(56)$ & $63.6 \%(7)$ & 0.756 \\
\hline$>25$ & $47.8 \%(43)$ & $36.4 \%(4)$ & \\
\hline \multicolumn{4}{|c|}{ Diabetes mellitus } \\
\hline Yes & $44.4 \%(40)$ & $36.4 \%(4)$ & $>0.999$ \\
\hline No & $65.6 \%(59)$ & $63.6 \%(7)$ & \\
\hline \multicolumn{4}{|c|}{ Hypertension } \\
\hline Yes & $74.4 \%(67)$ & $63.6 \%(7)$ & 0.748 \\
\hline No & $35.6 \%(32)$ & $36.4 \%(4)$ & \\
\hline \multicolumn{4}{|l|}{ Smoking } \\
\hline Yes & $54.4 \%(49)$ & $36.4 \%(4)$ & 0.530 \\
\hline No & $55.6 \%(50)$ & $63.6 \%(7)$ & \\
\hline \multicolumn{4}{|c|}{ Dyslipidemia } \\
\hline Yes & $35.6 \%$ (32) & $27.3 \%(3)$ & $>0.999$ \\
\hline No & $74.4 \%(67)$ & $72.7 \%(8)$ & \\
\hline \multicolumn{4}{|c|}{ Family history of coronary artery disease } \\
\hline Yes & $24.4 \%(22)$ & $9.1 \%(1)$ & 0.453 \\
\hline No & $85.6 \%(77)$ & $90.9 \%(10)$ & \\
\hline
\end{tabular}

TABLE 2: Features of the demography and clinical values by severity of the TIMI flow grade III after the procedure

$\mathrm{TIMI}=$ thrombolysis in myocardial infarction

\section{Discussion}

This study was performed to evaluate the chances of MVD and subsequent TIMI flow grade in patients who have undergone primary PCI. We observed that half (50\%) of the patients had MVD, and a TIMI flow grade of III was attained in $90 \%$ of the patients after primary PCI. Slow flow/no-reflow (TIMI flow grades 0-II) after primary PCI plays a substantial role in the eventual diagnosis of the patients. However, we have observed no significant association between post-procedure TIMI flow grade and the number of vessels involved.

Multivessel involvement in patients with STEMI is not an uncommon finding; 50\% MVD in our study is aligned with the reported frequency of as high as $44 \%$ to $66 \%$ in patients with STEMI [10-12,14,15]. MVD has been proven to be a significant prognostic marker with significantly higher rates of associated morbidities and mortalities [10-12]. Multivessel involvement is found to be associated with various clinical and 
demographic factors such that patients with MVD are older in age as compared to patients with SVD, comorbid conditions such as HTN and DM are more common, and patients with MVD have more complex and severe diseases with a higher proportion of type $\mathrm{C}$ lesions and a higher thrombus grade $[10,12,14,16,17]$. In this study, MVD was found to be also associated with dyslipidemia, family history of premature CADs, and female gender.

The primary aim in the treatment of patients with STEMI is successful reperfusion therapy, which may be performed through physical or pharmacological intervention $[18,19]$. The goal of all treatments, whether physical or pharmacological, is to restore the blood flow within the vessels. PCI was attempted for the culprit artery only, and almost 90\% of the subjects exhibited TIMI flow grade III after the procedure. Primary PCI is not successful in restoring myocardial perfusion in a significant number of patients. In our study, approximately $10 \%$ of subjects exhibited TIMI flow grade 0 to II after the procedure. This is referred to as the slow/no-reflow phenomenon and is often linked with negative outcomes following the procedure [20-24]. The exact mechanism behind the slow/no-reflow phenomenon is not clear; however, various clinical characteristics are associated with this phenomenon such as advanced age, delayed reperfusion, a longer length of the lesion, collateral flow, decreased left ventricular ejection fraction, MVD, thrombus grade, increased heart rate, elevated creatinine, and presence of comorbid conditions such as DM and HTN [20,2326].

Therefore, both multivessel involvement and post-procedure slow/no-reflow have prognostic implications in patients with STEMI. Primary PCI in these patients is not only safe but also a key strategy for the early restoration of the myocardium when performed timely. For patients with MVD, culprit lesion-only PCI strategy is a common practice. However, multivessel PCI strategy can be adopted in certain cases. With its potential benefits, it may also possess certain clinical disadvantages such as hemodynamics of the patients may be compromised due to extended duration and increased use of contrast during the intervention of non-culprit lesion [10,27-30].

One of the limitations of our study is a relatively smaller sample size, but it was conducted at the largest cardiac center of the country, covering almost all the population subgroups. Another limiting factor of our study was the male-centric nature of our sample, with almost $81 \%$ being represented by men. Therefore, the data cannot be implicated to conclude gender-based differences in TIMI flow grade after primary PCI.

\section{Conclusions}

Post-procedure TIMI flow grade III was accomplished in most subjects with or without MVD. Therefore, primary PCI plays a vital role in the early restoration of the blood flow to the myocardium during STEMI regardless of the number of vessels involved.

\section{Additional Information \\ Disclosures}

Human subjects: Consent was obtained by all participants in this study. Animal subjects: All authors have confirmed that this study did not involve animal subjects or tissue. Conflicts of interest: In compliance with the ICMJE uniform disclosure form, all authors declare the following: Payment/services info: All authors have declared that no financial support was received from any organization for the submitted work. Financial relationships: All authors have declared that they have no financial relationships at present or within the previous three years with any organizations that might have an interest in the submitted work. Other relationships: All authors have declared that there are no other relationships or activities that could appear to have influenced the submitted work.

\section{References}

1. Mensah GA, Roth GA, Fuster V: The global burden of cardiovascular diseases and risk factors . J Am Coll Cardiol. 2019, 74:2529-2532. 10.1016/j.jacc.2019.10.009

2. Roth GA, Abate D, Abate KH, et al.: Global, regional, and national age-sex-specific mortality for 282 causes of death in 195 countries and territories, 1980-2017: a systematic analysis for the Global Burden of Disease Study 2017. Lancet. 2018, 392:1736-1788. 10.1016/S0140-6736(18)32203-7

3. Kyu HH, Abate D, Abate KH, et al.: Global, regional, and national disability-adjusted life-years (DALYs) for 359 diseases and injuries and healthy life expectancy (HALE) for 195 countries and territories, 1990-2017: a systematic analysis for the Global Burden of Disease Study 2017. Lancet. 2018, 392:1859-1922. 10.1016/S0140-6736(18)32335-3

4. Keeley EC, Hillis LD: Primary PCI for myocardial infarction with ST-segment elevation. N Engl J Med. 2007 356:47-54. 10.1056/NEJMct063503

5. Gupta M, Singh N, Verma S: South Asians and cardiovascular risk. Circulation. 2006, 113:924-929. 10.1161/CIRCULATIONAHA.105.583815

6. Joshi P, Islam S, Pais P, et al.: Risk factors for early myocardial infarction in South Asians compared with individuals in other countries. JAMA. 2007, 297:286-294. 10.1001/jama.297.3.286

7. Lopez AD, Mathers CD, Ezzati M, Jamison DT, Murray CJ: Global and regional burden of disease and risk factors, 2001: systematic analysis of population health data. Lancet. 2006, 367:1747-1757. 10.1016/S01406736(06)68770-9 
8. Mohan V, Deepa R, Shanthi Rani S, Premalatha G: Prevalence of coronary artery disease and its relationship to lipids in a selected population in South India. J Am Coll Cardiol. 2001, 38:682-687. 10.1016/S07351097(01)01415-2

9. Gupta R, Gupta VP, Sarna M, et al.: Prevalence of coronary heart disease and risk factors in an urban Indian population: Jaipur Heart Watch-2. Indian Heart J. 2002, 54:59-66.

10. Batra MK, Rasool SI, Solangi BA, Khan N, Karim M, Hassan Rizvi SN: Multivessel disease as a prognostic marker in patients presenting for primary percutaneous coronary intervention. J Ayub Med Coll Abbottabad. 2018, 30:534-538.

11. Karamfiloff KK, Stoykova ZD, Georeva PG, Trendafilova DK, Jorgova JB: Multivessel disease as a prognostic factor for mortality in STEMI patients. J Biomed Clin Res. 2015, 8:30-34. 10.1515/jbcr-2015-0148

12. Lekston A, Tajstra M, Gąsior M, et al.: Impact of multivessel coronary disease on one-year clinical outcomes and five-year mortality in patients with ST-elevation myocardial infarction undergoing percutaneous coronary intervention. Kardiol Pol. 2011, 69:336-343.

13. Kern MJ, Moore JA, Aguirre FV, et al.: Determination of angiographic (TIMI grade) blood flow by intracoronary doppler flow velocity during acute myocardial infarction. Circulation. 1996, 94:1545-1552. 10.1161/01.CIR.94.7.1545

14. Steg PG, James SK, Atar D, et al.: ESC Guidelines for the management of acute myocardial infarction in patients presenting with ST-segment elevation. Eur Heart J. 2012, 33:2569-2619. 10.1093/eurheartj/ehs215

15. de Waha S, Eitel I, Desch S, Fuernau G, Pöss J, Schuler G, Thiele H: Impact of multivessel coronary artery disease on reperfusion success in patients with ST-elevation myocardial infarction: a substudy of the AIDA STEMI trial. Eur Hear J Acute Cardiovasc Care. 2017, 6:592-600. 10.1177/2048872615624240

16. Toma A, Stähli BE, Gick M, et al.: Impact of multivessel versus single-vessel disease on outcomes after percutaneous coronary interventions for chronic total occlusions. Clin Res Cardiol. 2017, 106:428-435. 10.1007/s00392-016-1072-z

17. van der Schaaf RJ, Timmer JR, Ottervanger JP, et al.: Long-term impact of multivessel disease on causespecific mortality after ST elevation myocardial infarction treated with reperfusion therapy. Heart. 2006, 92:1760-1763. 10.1136/hrt.2005.086058

18. Kurowski V, Giannitsis E, Killermann DP, et al.: The effects of facilitated primary PCI by guide wire on procedural and clinical outcomes in acute ST-segment elevation myocardial infarction. Clin Res Cardiol. 2007, 96:557-565. 10.1007/s00392-007-0532-x

19. Ribichini F, Ferrero V, Wijns W: Reperfusion treatment of ST-elevation acute myocardial infarction. Prog Cardiovasc Dis. 2004, 47:131-157. 10.1016/j.pcad.2004.07.007

20. Ashraf T, Khan MN, Afaque SM, et al.: Clinical and procedural predictors and short-term survival of the patients with no reflow phenomenon after primary percutaneous coronary intervention. Int J Cardiol. 2019, 294:27-31. 10.1016/j.ijcard.2019.07.067

21. Reffelmann T: The 'no-reflow' phenomenon: basic science and clinical correlates . Heart. 2002, 87:162-168. 10.1136/heart.87.2.162

22. Sabin P, Koshy AG, Gupta PN, et al.: Predictors of no-reflow during primary angioplasty for acute myocardial infarction, from Medical College Hospital, Trivandrum. Indian Heart J. 2017, 69:34-45. 10.1016/.ihj.2016.12.012

23. Abdi S, Rafizadeh O, Peighambari M, Basiri H, Bakhshandeh H: Evaluation of the clinical and procedural predictive factors of no-reflow phenomenon following primary percutaneous coronary intervention. Res Cardiovasc Med. 2015, 4:4. 10.5812/cardiovascmed.4(2)2015.25414

24. Ndrepepa G, Tiroch K, Keta D, et al.: Predictive factors and impact of no reflow after primary percutaneous coronary intervention in patients with acute myocardial infarction. Circ Cardiovasc Interv. 2010, 3:27-33. 10.1161/CIRCINTERVENTIONS.109.896225

25. Fajar JK, Heriansyah T, Rohman MS: The predictors of no reflow phenomenon after percutaneous coronary intervention in patients with ST elevation myocardial infarction: a meta-analysis. Indian Heart J. 2018, 70:406-418. 10.1016/j.ihj.2018.01.032

26. Zhou H, He XY, Zhuang SW, et al.: Clinical and procedural predictors of no-reflow in patients with acute myocardial infarction after primary percutaneous coronary intervention. World J Emerg Med. 2014, 5:96102. 10.5847/wjem.j.issn.1920-8642.2014.02.003

27. Bainey KR, Mehta SR, Lai T, Welsh RC: Complete vs culprit-only revascularization for patients with multivessel disease undergoing primary percutaneous coronary intervention for ST-segment elevation myocardial infarction: a systematic review and meta-analysis. Am Heart J. 2014, 167:1-14.e2. 10.1016/j.ahj.2013.09.018

28. Gershlick AH, Khan JN, Kelly DJ, et al.: Randomized trial of complete versus lesion-only revascularization in patients undergoing primary percutaneous coronary intervention for STEMI and multivessel disease. J Am Coll Cardiol. 2015, 65:963-972. 10.1016/j.jacc.2014.12.038

29. Rasoul S, van Ommen V, Vainer J, et al.: Multivessel revascularisation versus infarct-related artery only revascularisation during the index primary PCI in STEMI patients with multivessel disease: a meta-analysis. Neth Heart J. 2015, 23:224-231. 10.1007/s12471-015-0674-9

30. Li Z, Zhou Y, Xu Q, Chen X: Staged versus one-time complete revascularization with percutaneous coronary intervention in STEMI patients with multivessel disease: a systematic review and meta-analysis. PLoS One. 2017, 12 :e0169406. 10.1371/journal.pone.0169406 